\title{
Critical analysis of temporal climate change and ensuing frequency of crop yield constraining temperatures
}

\author{
S.K. JALOTA ${ }^{1}$, PRABHJYOT KAUR ${ }^{2}$, JATINDER KAUR ${ }^{2}$, P.K. KINGRA ${ }^{2}$ and B.B. VASHISHT ${ }^{1}$ \\ ${ }^{1}$ Department of Soil Science, Punjab Agricultural University, Ludhiana, Punjab, India; \\ ${ }^{2}$ Department of Climate Change \& Agricultural Meteorology, Punjab Agricultural University, Ludhiana, Punjab, India \\ Corresponding author Email: bharatpau@pau.edu
}

\begin{abstract}
Critical analysis of magnitudes andtrends of temporal changes in maximum (Tmax) and minimum (Tmin) temperatures as well as rainfall during three time series i.e. past (observed data, 1970-1990), present (observed data, 1989-2018) and future (bias corrected modelled data, 2021-2050) reveals that on the whole, inter-series mean of all the three climate parameters increased, and variation decreased in future time series. The magnitude of these trends varied with the model as well as scenario; was highest in RCP 8.5 scenario. Intra-series trends at annual and seasonal scales are dictated by inconsistent monthly trends. This study also adds that decline incrop yields of rice-wheat system with warming in future can be ascribed to increased frequency of days having yield constraining temperatures (above ceiling and below critically low during crop growth and reproduction stages) rather than their elevated magnitudes only as anticipated previously.
\end{abstract}

Key words: Climate parameters, RCP, bias correction,time series trends, rice-wheat system

Climate change is a continuous process; it was at works in the past, is at present and would be in future. The ensuing changes in climate parameters i.e. maximum (Tmax) and minimum (Tmin) temperatures, rainfall (RF), solar radiation, relative humidity and wind speed may be temporal (daily, monthly, seasonally and annually; decade wise, century wise and beyond); spatial (location and region) and varies in trend (increasing or decreasing) as well ascontinuity (gradual or abrupt). The spatial and temporal climate data for past and present is readily available as observations, but estimates of future data are unwieldy, and is unfolded by projections, prediction and forecast from (i) stochastic simulations and (ii) climate models like general circular (GCM), regional climate (RCM) based on emission scenario and representative concentration pathways (RCP) based on radiative forcing. Though the climate change in future is very much uncertain yet is dominantly characterised by increasing temperature. These changes are not limited to climate change only, but have produced occasional extremes (record breaking events) which caused crop and human losses at global level. The spatial and temporal changes in weather variables due to global warming not only changes the climate, but also alter the hydrological cycle; and have agronomic, environmental and economic impacts (Hillel and Rosenzweig, 2013; Jalota et al., 2013; Kang and Banga, 2013). It has also been recognized that increased magnitude of temperatures and number of days above ceiling and below critical low temperatures affect crop yields by changing crop physiological processes and phenology. Keeping this in view, the present study was undertaken with the objectives to (i) statistically analyze the magnitude and trends of interand intra-time series changes in climate parameters like Tmax, Tmin and RF and (ii) changes in frequency of the days having above ceiling and below critically low temperatures constraining crop yield in rice-wheat system during past, present and future time series.

\section{MATERIALS AND METHODS}

\section{Study area}

The study pertains to a climatic zone that is characterized by hot dry semi-arid with summers (April to June months with maximum temperature of $35-39^{\circ} \mathrm{C}$ ) and cool winters (December to February months with minimum temperature $6-9^{\circ} \mathrm{C}$ ). The temperature reaches as high as $46^{\circ} \mathrm{C}$ in some days during summer months of May and June, comprising the hottest months of the year. January is the coldest month of the year, occasionally drops to $2-3^{\circ} \mathrm{C}$. The major portion of the rain is through summer monsoons, which generally set in July and continue till September covering Kharif season (June to October). During Rabi season (November to May) the rains are by western 

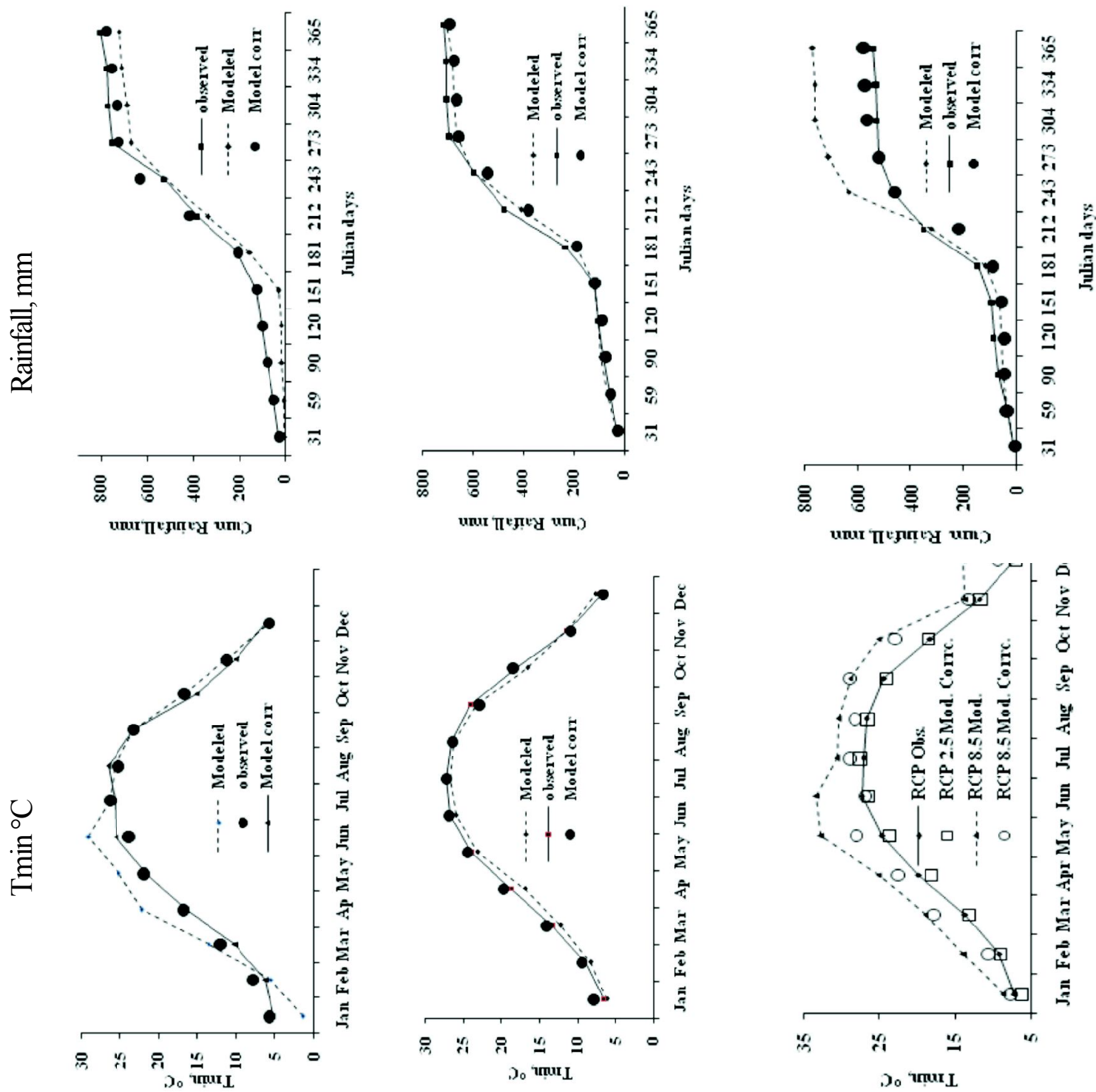

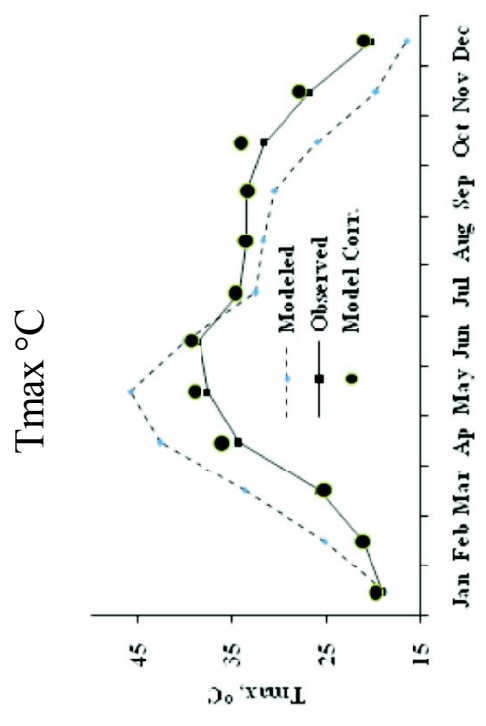

(WDy)

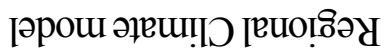

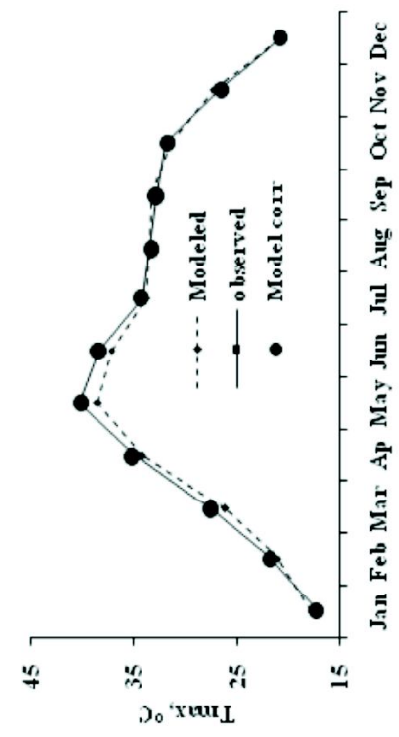

(แอฺแ!̣)

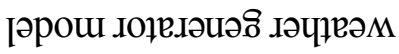
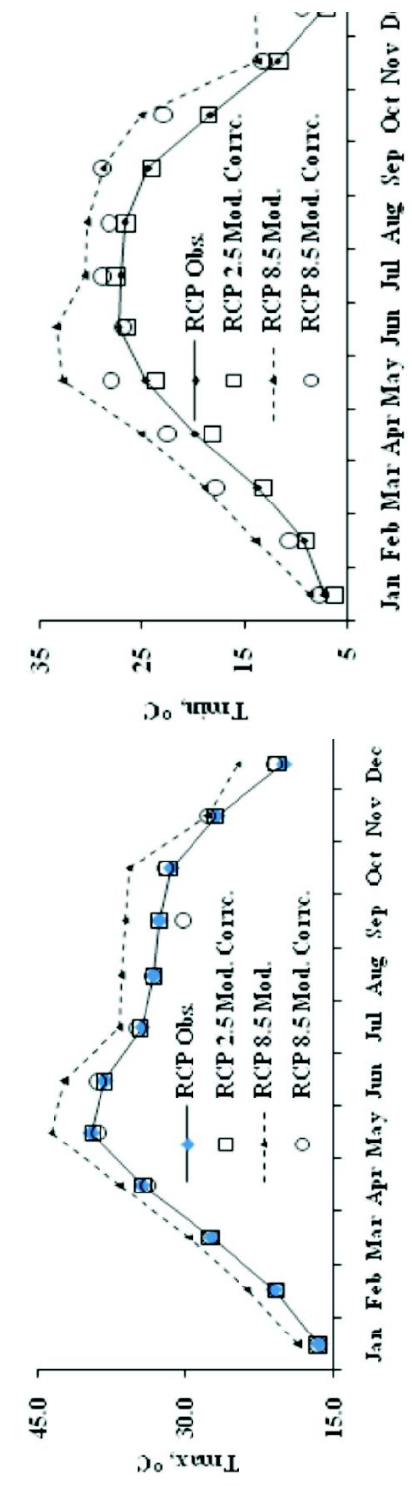

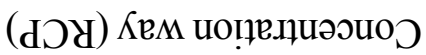

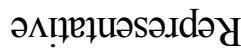


disturbances. The annual average rainfall over last 30 years (1989-2018) is $760 \pm 227 \mathrm{~mm}$. The main cropping system is rice-wheat.

\section{Collection of the climate data}

In the study, observed past (1971-1990) and present (1988-2018) climate data of different parameters (Tmax, Tmin and RF) recorded by Department of Climate Change \& Agricultural Meteorology at Punjab Agricultural University, Ludhiana (Latitude $32^{\circ} 5^{\prime \prime}$, longitude $75^{\circ} 5^{\prime \prime}$ at $247 \mathrm{~m}$ above sea level) was considered. The future modelled data of the same parameters was obtained from different sources i.e. Regional climate model (RCM-PRECIS) based on Emission scenario (SERES) borrowed from Indian Meteorological Institute, Pune (India), estimated by ClimGen model (Stockle et al., 1999) using the observed data of 1989-2018 and retrieved daily data from the site http:// gismap.ciat.cgiar.org/MarkSimGCM/ for four representative concentration pathways (RCP) scenarios viz. 2.6, 4.5, 6.0 and 8.5 in the four models i.e. CSIRO-Mk 3-60, FIO, F1O-ESM and IPSL-CM5A-MR. The weather parameters of various locations of Punjab generated by ClimGen model was validated by Bal et al. (2008) and reported close agreement for both maximum and minimum temperatures.

\section{Bias estimation and Removal}

The bias in the future modelled data of Tmax, Tmin and RF was estimated as difference between observed and modelled data of 1970-1985 for RCM, 1989-2003 for ClimGen and 2010-2015 for RCP on daily, monthly and annual time scales. Difference method for rainfall, and Leander and Buishand (2007) for Tmax and Tmin at monthly scale was used for removing the bias and correcting the modelled data (Jalota et al., 2013).

\section{Statistical analysis of time series data}

The statistical significance of the trend in annual, seasonal and monthly series was analysed by using the nonparametric Mann-Kendall (MK) test (Mann, 1945; Kendall, 1975). The Mann-Kendall statistic is given by:

$$
S=\sum_{i=1}^{n-1} \sum_{j=i+1}^{n} \operatorname{sign}\left(x_{j}-x_{i}\right)
$$

Where, $\mathrm{n}$ is the number of data points $\mathrm{x}_{\mathrm{j}}$ and $\mathrm{x}_{\mathrm{i}}$ are two generic sequential data values.
The standardized test statistic $\mathrm{Z}$ that provides final conclusions of Mann-Kendall is given by:

$$
Z=\left\{\begin{array}{cc}
\frac{S-1}{\sqrt{\operatorname{Var}}(S)} & \text { if } S>0 \\
0 & \text { if } S=0 \\
\frac{S+1}{\sqrt{\operatorname{Var}}(S)} & \text { if } S<0
\end{array}\right.
$$

Where

$$
\operatorname{Var}(s)=\frac{1}{18}[n(n-1)(2 n+5)]
$$

Presence of a statistically significant trend was evaluated by using the $Z$ value. Positive value of $Z$ indicates an increasing trend, while a negative value of $Z$ indicates a decreasing trend..The magnitude of the trend in the annual, seasonal and monthly time series data of temperature and rainfall was determined by the Sen's estimator (Q), the median of slopes of all data value pairs, using Sen's nonparametric method (Sen, 1968).

$$
\mathrm{Q}=\operatorname{median}\left[\frac{\mathrm{x}_{\mathrm{j}}-\mathrm{x}_{\mathrm{i}}}{\mathrm{j}-\mathrm{i}}\right] \text { for all } \mathrm{i}<j
$$

where, $\mathrm{Q}$ is the slope between data points $\mathrm{x}_{\mathrm{j}}$ and $\mathrm{x}_{\mathrm{i}}$ measured at times $j$ and $i$ respectively. A positive estimation of $\mathrm{Q}$ is likely to show upward trend and negative values is likely to show downward trend.

\section{Frequency of crop yield constraint temperatures}

From daily Tmax and Tmin data in all the three time series, the number of days above ceiling temperatures and below critically low temperatures during vegetative growth as well as reproductive stages that affects the grain yield were calculated in rice and wheat crops. In rice crop ceiling temperature considered was $>37^{\circ} \mathrm{C}$ during crop growth and $>32^{\circ} \mathrm{C}$ during flowering for Tmax (Chahal et al., 2007). The Tmin values considered were $>25^{\circ} \mathrm{C}$ and $<15^{\circ} \mathrm{C}$ during crop growth. In wheat crop, ceiling temperatures was considered as $>29^{\circ} \mathrm{C}$ during whole crop season and $>34^{\circ} \mathrm{C}$ during grain development and maturity (120-150 days) for Tmax. For Tmin temperatures were $>11^{\circ} \mathrm{C}$ and $<3^{\circ} \mathrm{C}$ during growth period (Vashisht et al., 2019).

\section{RESULTS AND DISCUSSION}

\section{Typical biases of the models}

Monthly averages of the observed and modelled 


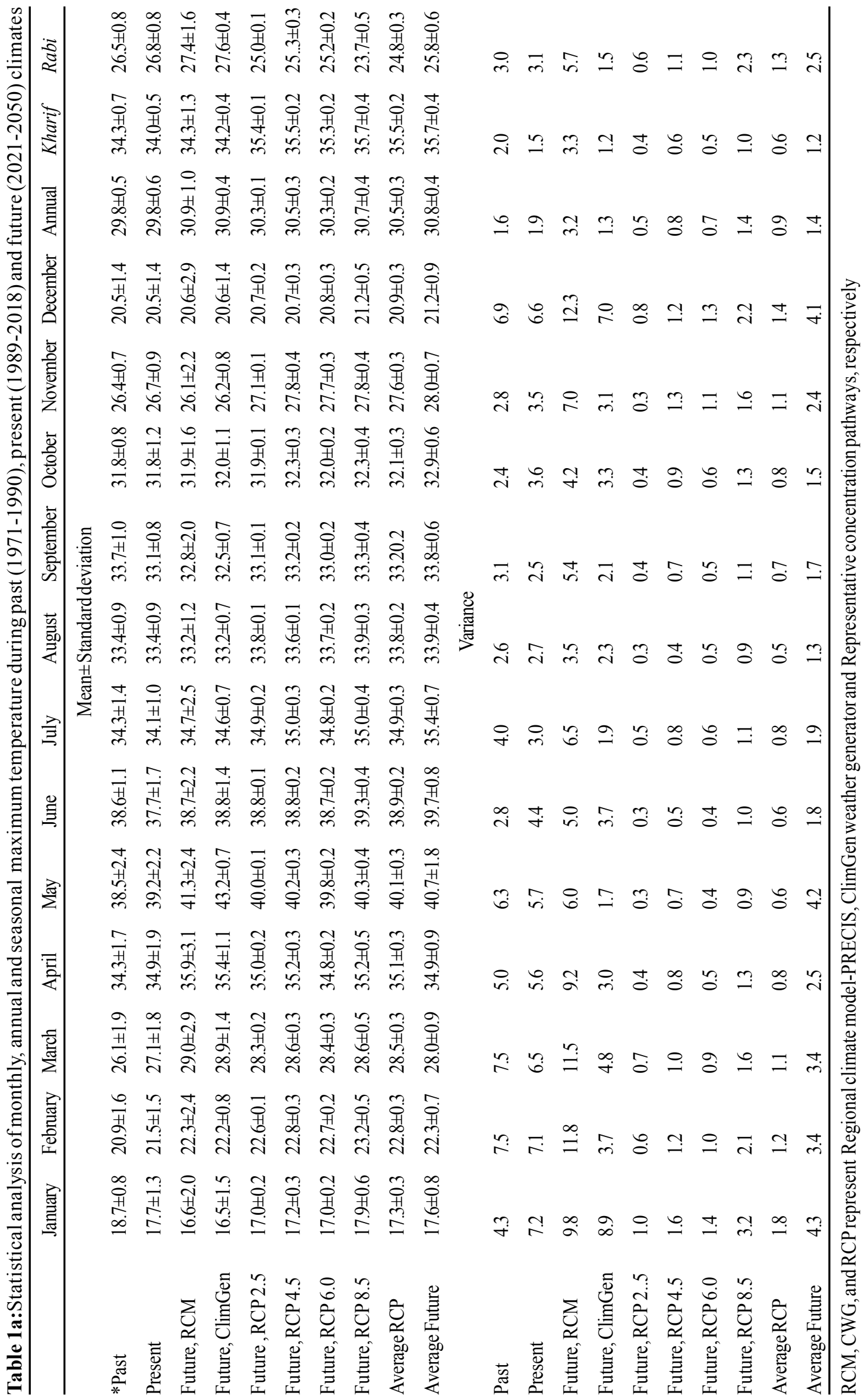




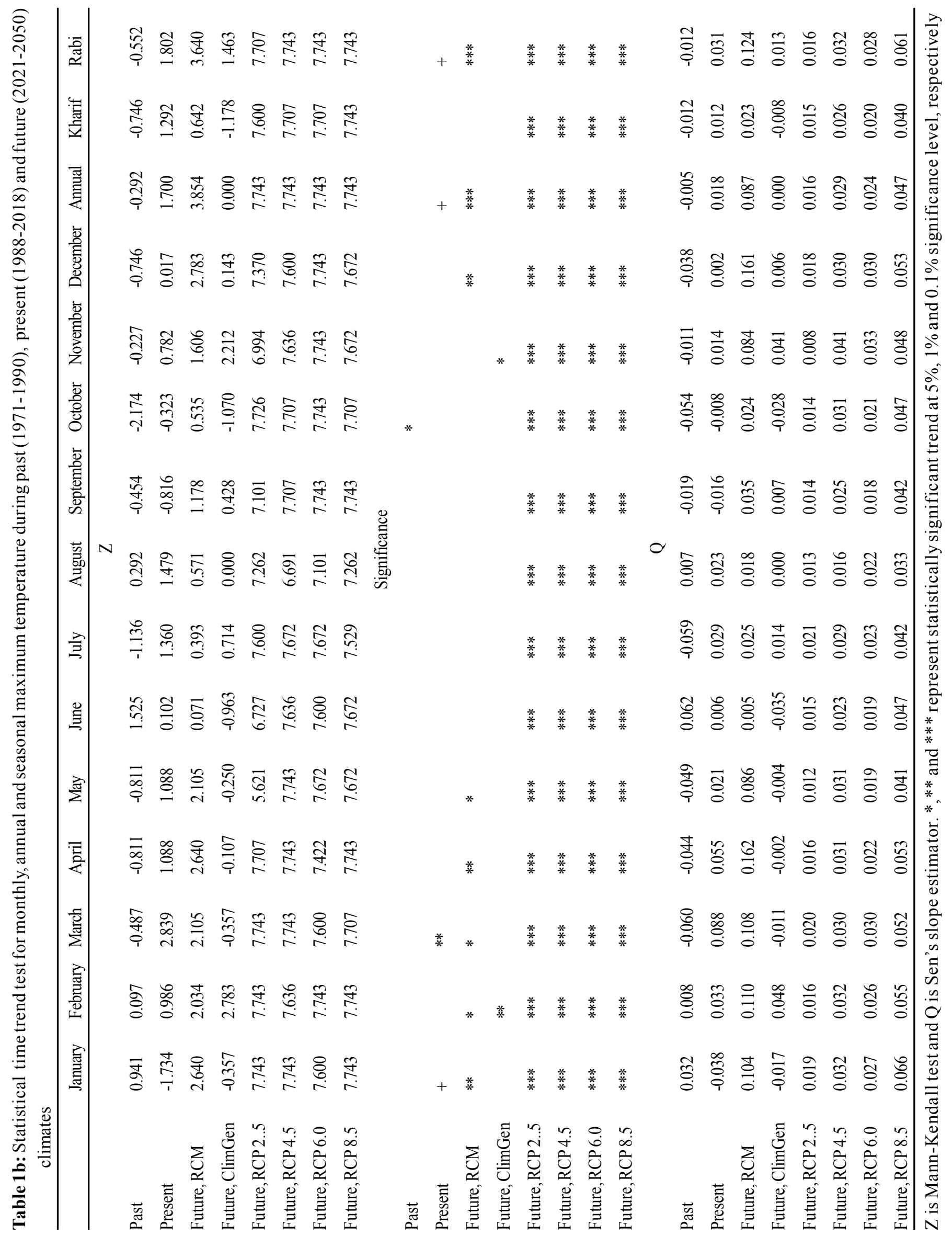




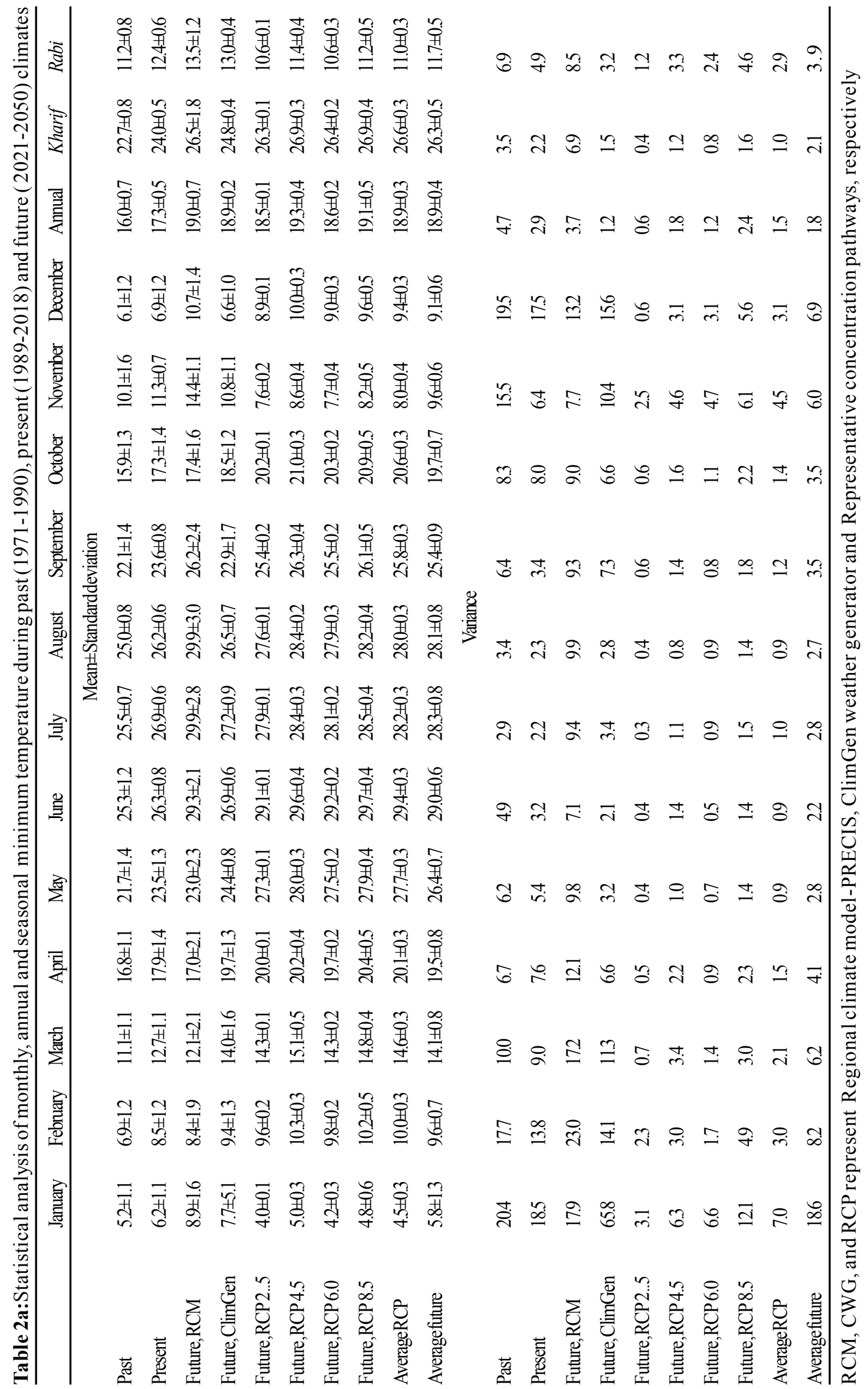




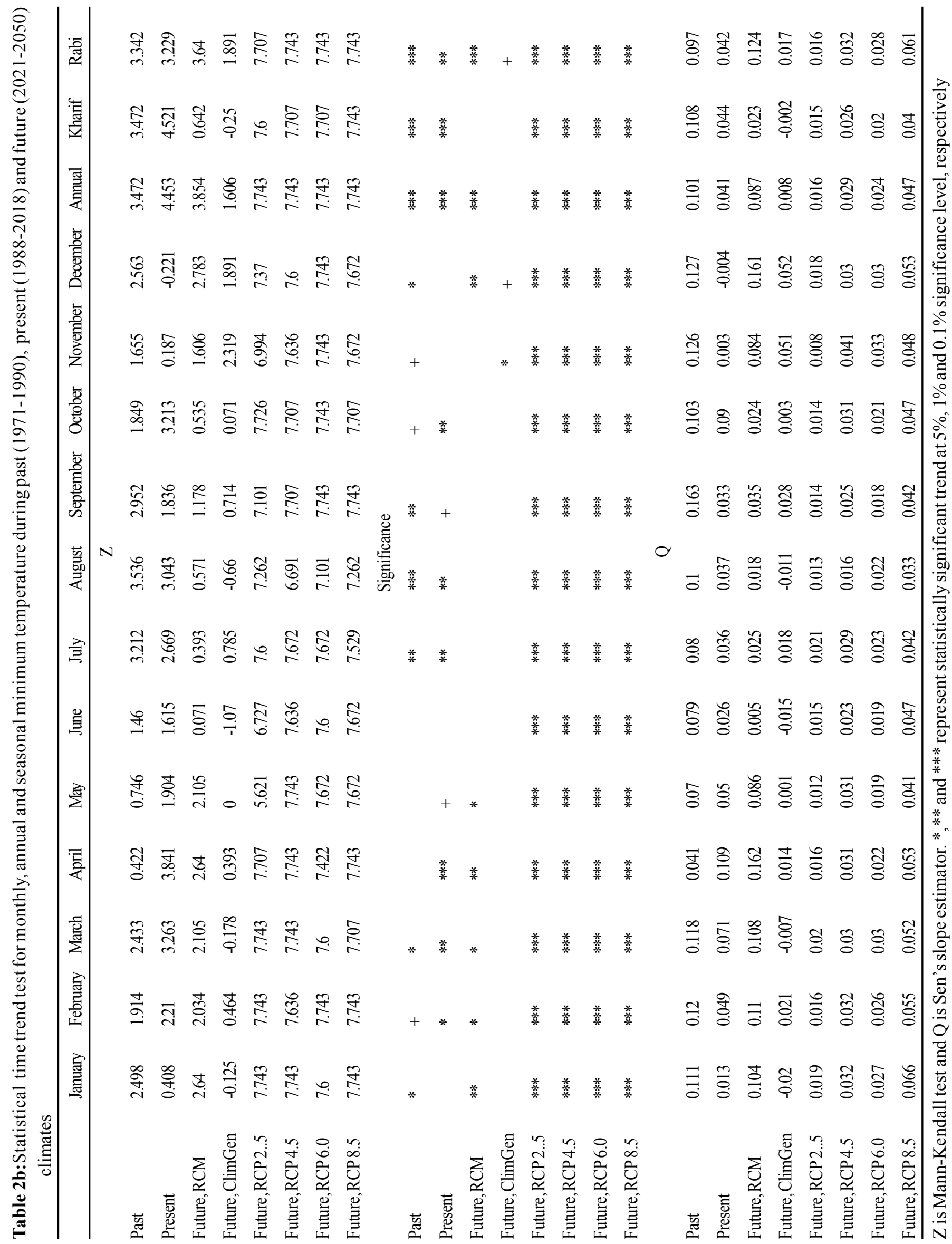




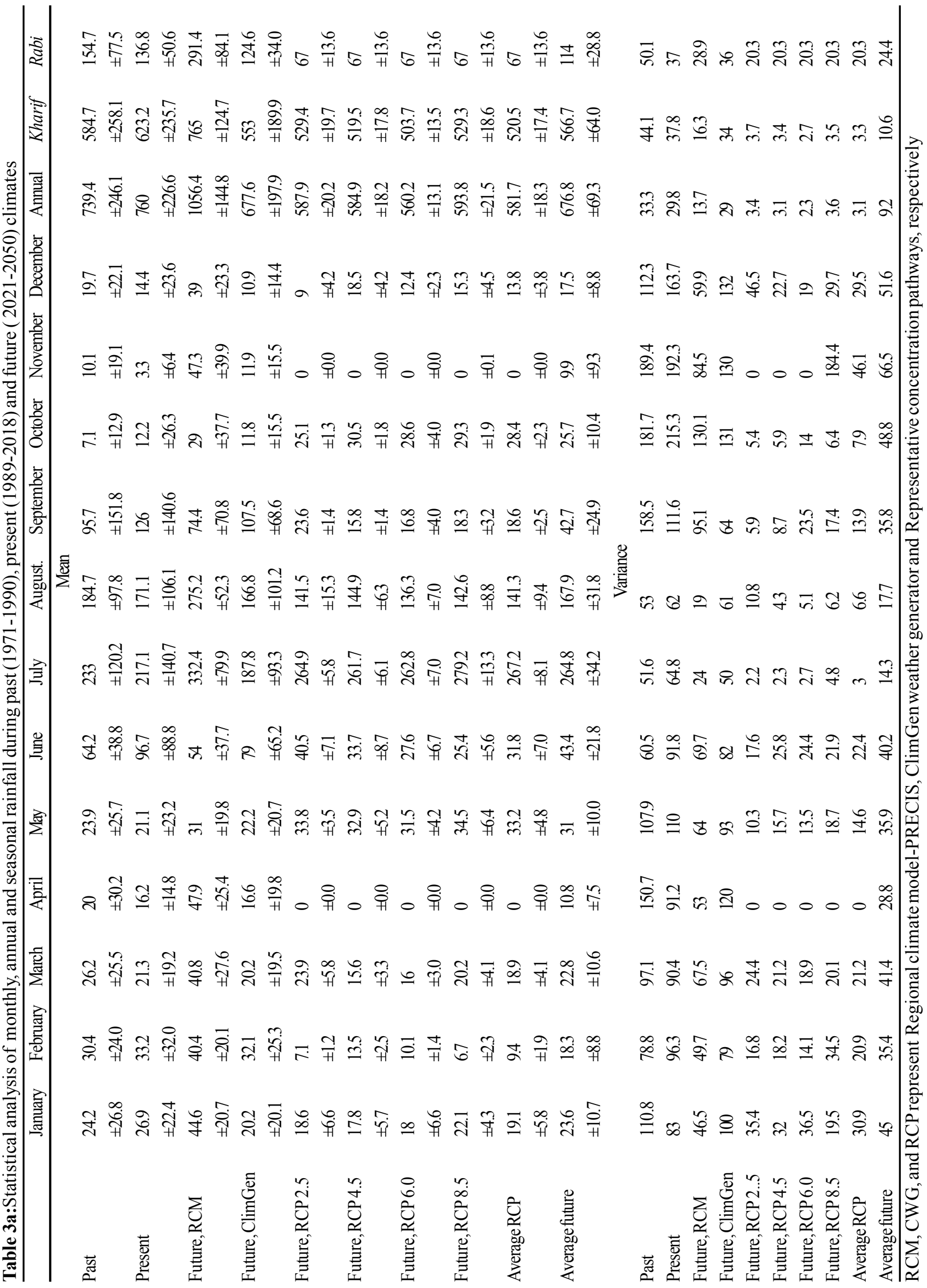




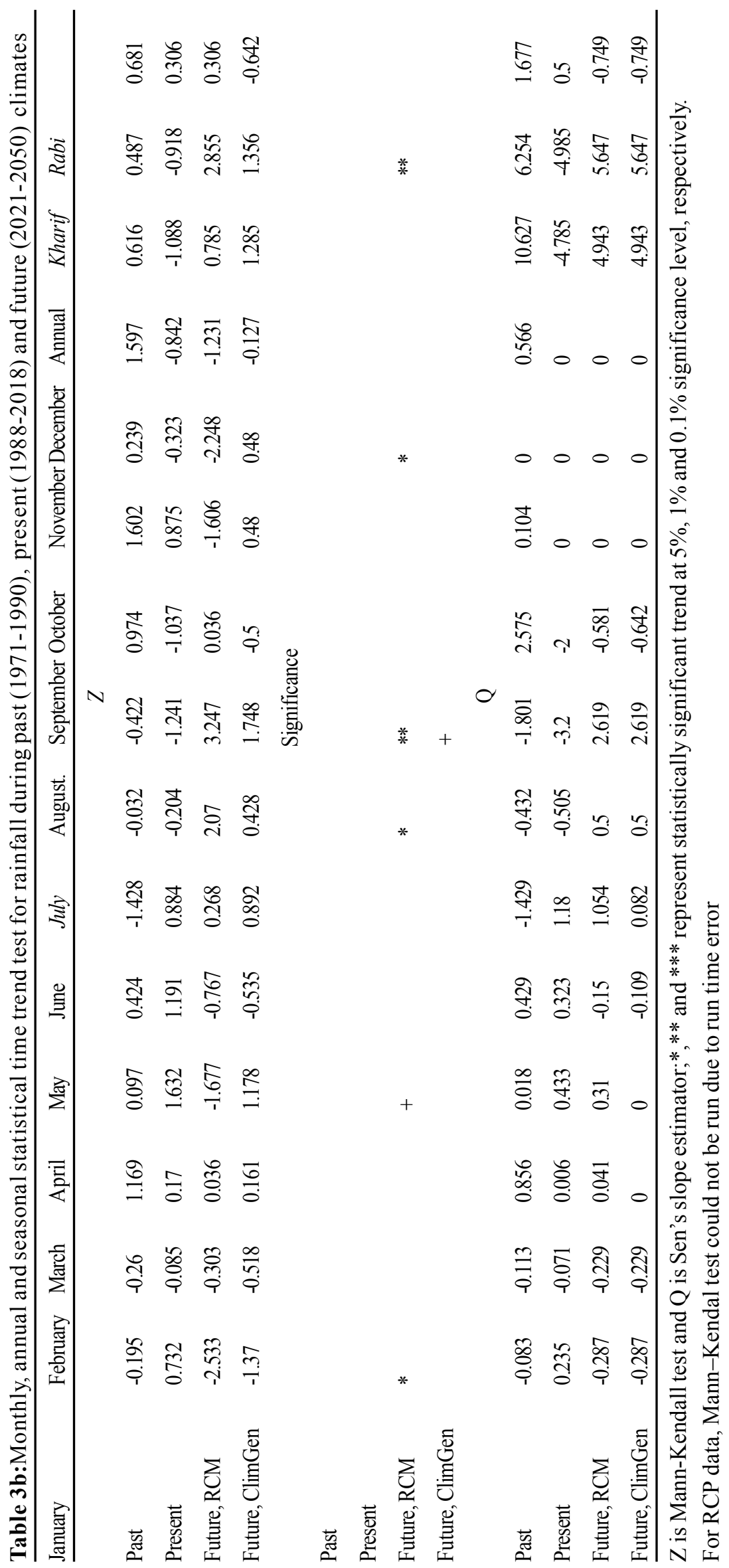


Table 4: Number of days above ceiling and below critically low temperatures in rice and wheat crops during past, present and future time series

\begin{tabular}{|c|c|c|c|c|c|c|c|c|}
\hline \multicolumn{9}{|c|}{ Rice } \\
\hline & \multicolumn{4}{|c|}{$\operatorname{Tmax}$} & \multicolumn{4}{|c|}{ Tmin } \\
\hline & \multicolumn{2}{|c|}{$>37^{\circ} \mathrm{C}$} & \multicolumn{2}{|c|}{$>34^{\circ} \mathrm{C}$ during flowering } & \multicolumn{2}{|c|}{$>25^{\circ} \mathrm{C}$} & \multicolumn{2}{|c|}{$<15^{\circ} \mathrm{C}$} \\
\hline & Range & Average & Range & Average & Range & Average & Range & Average \\
\hline Past & $16-57$ & 29.1 & Jun-36 & 20.1 & $16-73$ & 52.9 & $0-0$ & 0 \\
\hline Present & May-38 & 21.6 & Apr-30 & 17.3 & $50-94$ & 75.6 & $0-1$ & 0.1 \\
\hline \multicolumn{9}{|l|}{ Future, RCM } \\
\hline Future, ClimGen & $13-34$ & 24.5 & Sep-27 & 16.4 & $63-90$ & 77.7 & $0-0$ & 0 \\
\hline Future, RCP2.6 & $29-33$ & 30.9 & $13-15$ & 13.6 & $98-107$ & 104.2 & $0-0$ & 0 \\
\hline Future, RCP 4.0 & $31-35$ & 33.4 & $15-19$ & 16.9 & $103-110$ & 108.4 & $0-0$ & 0 \\
\hline Future, RCP 6.5 & $27-36$ & 31.9 & Dec-18 & 15.8 & $98-109$ & 105 & $0-0$ & 0 \\
\hline \multirow[t]{5}{*}{ Future, RCP8.5 } & $29-35$ & 31 & $15-22$ & 17.1 & $104-112$ & 109.4 & $0-0$ & 0 \\
\hline & \multicolumn{8}{|c|}{ Wheat } \\
\hline & \multicolumn{4}{|c|}{ Tmax } & \multicolumn{4}{|c|}{ Tmin } \\
\hline & \multicolumn{2}{|c|}{ Days $>29^{\circ} \mathrm{C}$} & \multicolumn{2}{|c|}{$\begin{array}{c}\text { Days }>34^{\circ} \mathrm{C} \text { in } 120-150 \\
\text { days after sowing }\end{array}$} & \multicolumn{2}{|c|}{$>11^{\circ} \mathrm{C}$} & \multicolumn{2}{|c|}{$<3^{\circ} \mathrm{C}$} \\
\hline & Range & Average & Range & Average & Range & Average & Range & Average \\
\hline Past & Aug-44 & 27.3 & $0-2$ & 0.2 & $30-69$ & 48.8 & $0-26$ & 12.5 \\
\hline Present & $17-50$ & 30.5 & $0-10$ & 1.1 & $52-81$ & 65.8 & $0-27$ & 5.6 \\
\hline Future, RCM & & & & & & & & \\
\hline Future, ClimGen & $26-47$ & 35.7 & $0-9$ & 1.9 & $47-81$ & 66.9 & Jan-13 & 8 \\
\hline Future, RCP2.6 & $30-34$ & 31.9 & $0-0$ & 0 & $70-75$ & 73.6 & $17-21$ & 18.9 \\
\hline Future, RCP 4.0 & $42-52$ & 48.8 & $0-0$ & 0 & $72-85$ & 78.1 & 4.7 & $0-0$ \\
\hline Future, RCP6.5 & $51-59$ & 55.8 & $0-0$ & 0 & $70-80$ & 75 & $14-23$ & 17.8 \\
\hline Future, RCP8.5 & $40-54$ & 47.1 & $0-0$ & 0 & $73-91$ & 81.6 & May-18 & 12 \\
\hline
\end{tabular}

Tmax, Tmin and RF showed that the annual cycle of the modelled temperatures reasonably represented the observed (Figure 1). However, the modelled and observed values were dissimilar and varied with the models. For instance, modelled Tmax was more than the observed Tmax in the months from February to May and less from July to December in PRECIS model; almost comparable in ClimGen; and more in all months except October in RCP. Modelled Tmin also followed the trend similar to that of modelled Tmax in all the three models. In case of RF, the modelled RF values were lower than that of the observed in all the months in RCM; in months from June to December in ClimGen; and up to July and reversed trend thereafter in RCP model.

\section{Correction of modelled data}

The results presented in Fig. 1 showed that discrepancy occurred in modelled and observed data of climate parameters. To minimize biases the best fitted bias correction functions for Tmax and Tmin suggested by Leander and Buishand (2007) method and for RF modified difference method were used. Correction functions are not shown for sake of brevity. Application of the correction functions narrowed downthe disparity in the modelled data and observed data of Tmax, Tmin and RF, as a result modelled and observed values came closer in terms of time trends and magnitude (Fig. 1). Residual mean square error (RMSE) of corrected modelled Tmax, Tmin and rainfall compared to modelled Tmax was very less.

\section{Climate change scenario}

With changed climate parameters (Tmax, Tmin and $\mathrm{RF}$ ), the resulting statistical parameters and time trends also 
changed. Statistical parameters (i.e. mean, tstandard deviation and variance) of climate parameters at monthly, annual and seasonal scales as well as time trend (magnitude of increase/decrease and significance) during past (19711990), present (1989-2018) and future (2021-2050) time series are presented in Tables 1-3.

\section{Maximum temperature}

Mean: For Tmax, annual mean \pm standard deviation of $29.8 \pm 0.5^{\circ} \mathrm{C}$ in the past and $29.8 \pm 0.6^{\circ} \mathrm{C}$ in present time series was increased to $30.9 \pm 1.0^{\circ} \mathrm{C}$ in future. The change in mean of Tmax for future varied with the model and scenario. For instance, it was more by $1.0^{\circ} \mathrm{C}$ with $\mathrm{RCM}, 1.1^{\circ} \mathrm{C}$ with ClmGen and $0.7^{\circ} \mathrm{C}$ with RCP (Table 1a). Tmax was more by 0.5, 0.7, 0.5 and $0.9^{\circ} \mathrm{C}$ in the RCPs scenarios - 2.6, 4.0, 6.5 and 8.5 , respectively. Seasonally, Tmax of $34.3 \pm 0.7^{\circ} \mathrm{C}$ during Kharif and $26.5 \pm 0.8^{\circ} \mathrm{C}$ during Rabi in the past were changed to $34.0 \pm 0.5^{\circ} \mathrm{C}$ and $26.8 \pm 0.8^{\circ} \mathrm{C}$ in present, and $35.7 \pm 0.4^{\circ} \mathrm{C}$ and $25.8 \pm 0.6^{\circ} \mathrm{C}$ in future, respectively. In future during Kharif and Rabi seasons the change compared to present was more by $0.3^{\circ} \mathrm{C}$ and $0.6^{\circ} \mathrm{C}$ in RCM; $0.2^{\circ} \mathrm{C}$ and $0.8^{\circ} \mathrm{C}$ with ClimGen; $1.5^{\circ} \mathrm{C}$ more and $2.0^{\circ} \mathrm{C}$ less with RCP. Amongst RCPs of 2.6, 4.0, 6.5 and 8.5 compared to present, the Tmax was increased by $1.4,1.5,1.3$ and $1.7^{\circ} \mathrm{C}$ during Kharif, and decreased by $1.8,1.5,1.6$ and $3.1^{\circ} \mathrm{C}$, respectively. Tmax also changed monthly. For instance, Tmax during the present time slice remained higher than the past in months of February to May and November. During future compared to present it would be more in all the months of the year except January. The magnitude would be higher in RCP 8.5 compared to other RCPs, RCM and ClimGen models.

Variation: The annual variance $(1.6 \%)$ in the past was increased to $1.9 \%$ in the present and will decrease to $1.4 \%$ in future (Table 1a). Seasonally during Kharif, the variance of 2.0 in the past was deceased to $1.5 \%$ in present and $1.2 \%$ in future. During Rabi variance of $3.0 \%$ in the past will increase marginally (by $0.1 \%$ ) during present and will decrease to $2.5 \%$ in future. In future relatively more variance was noticed with RCM model than ClimGen and RCP.

Time series trends: Within a time series of past, present and future, the annual, seasonal and monthly trends varied. For instance, at annual scale the trend was decreasing during the past, increasing during the present and future, however the change was significant during future only with RCM and RCPs (Table 1b). At seasonal scale, the trends are identical to the annual, but the trend with RCM was non-significant during Kharif season, At monthly scale, the trend was increasing for 4 months (January, February, June and August) during past, 10 months (all the months except September and October) during present and all the 12 months (January to December) during future time series. However, the increasing trend was significant only in the month of October during past, March during present and January to May as well as in December with RCM; February and November with ClimGen; and January to December with RCP.

\section{Minimum temperature}

Mean: The annual Tmin mean \pm standard deviation of $16.0 \pm 0.7^{\circ} \mathrm{C}$ in the past was increased to $17.3 \pm 0.5^{\circ} \mathrm{C}$ in present. In future it increased to $19.0 \pm 0.7^{\circ} \mathrm{C}$ with $\mathrm{RCM}$; $18.9 \pm 0.2^{\circ} \mathrm{C}$ with ClimGen and $18.9 \pm 0.2^{\circ} \mathrm{C}$ with $\mathrm{RCP}$ (Table 2a). Seasonally $\mathrm{Tmin}$ of $22.7 \pm 0.8^{\circ} \mathrm{C}$ during Kharif and $11.2 \pm 0.8^{\circ} \mathrm{C}$ during $R a b i$ in the past were increased to $24.0 \pm 0.5^{\circ} \mathrm{C}$ and $12.4 \pm 0.6^{\circ} \mathrm{C}$, respectively in present time series. In future time series the corresponding Tmin increased to $26.5 \pm 1.8^{\circ} \mathrm{C}$ and $13.5 \pm 1.2^{\circ} \mathrm{C}$ with $\mathrm{RCM} ; 24.8 \pm 0.4^{\circ} \mathrm{C}$ and $13.0 \pm 0.4^{\circ} \mathrm{C}$ with ClimGen; and $26.6 \pm 0.3^{\circ} \mathrm{C}$ and $11.0 \pm 0.3^{\circ} \mathrm{C}$ with RCP. Tmin also changed monthly. In the present time series Tmax remained higher than past in all months of the year. In future Tmin would be more in months of January, July, August and November. The magnitude of more would be higher in RCP 8.5 compared to other RCPs, RCM and ClimGen models.

Variation: The annual variance $4.7 \%$ in the past was decreased to $2.9 \%$ in the present and will decrease to $3.7 \%$ with RCM, $1.2 \%$ with Climgen and 0.6 to $2.4 \%$ with RCP in future, depending upon scenario. Seasonally during Kharif, the variance of 3.5 in the past was deceased to $2.2 \%$ in the present and increased to $69 \%$ with RCM, $1.5 \%$ with Climgen and 0.4 to $6.9 \%$ with RCPs in future. During Rabi variance of $6.9 \%$ would decrease to 4.9 in the present, increased to 8.5\%with RCM, decreased to 3.2 with ClimGen and decreased to 1.2 to $4.6 \%$ with RCPs in future.

Time series trends: Annual, seasonal and monthly time trends within a time series was increasing in the past, present and future except in January, March, June and August months and during Kharif season in ClimGen model (Table2b).

\section{Rainfall}

Mean: The annual rainfall mean with standard deviation of $739.4 \pm 246.1 \mathrm{~mm}$ in the past was increased to $760.0 \pm 226.6$ $\mathrm{mm}$ in present. In future it increased to $1056.4 \pm 144.8 \mathrm{~mm}$ with RCM; 677.6 $\pm 197.9 \mathrm{~mm}$ with ClimGen and decreased from $560 \pm 13.1$ to $593.8 \pm 21.5 \mathrm{~mm}$ with RCP (Table $3 \mathrm{a}$ ). 
Seasonally rainfall of $584.0 \pm 258.1 \mathrm{~mm}$ during Kharif and $154.7 \pm 77.5 \mathrm{~mm}$ during $R a b i$ in the past were increased to $623.2 \pm 235.7 \mathrm{~mm}$ and decreased to $136.8 \pm 50.6 \mathrm{~mm}$, respectively in present time slice. In future time slice the corresponding Tmin increased to $765.0 \pm 124.7 \mathrm{~mm}$ and $291.4 \pm 84.1 \mathrm{~mm}$ with RCM; $553.3 \pm 189.9 \mathrm{~mm}$ and $124.6 \pm 34.0$ with ClimGen; $503.7 \pm 13.6 \mathrm{~mm}$ and $67.0 \pm 13.6 \mathrm{~mm}$ to $529.4 \pm$ $52.0 \mathrm{~mm}$ and $67.0 \pm 13.6 \mathrm{~mm}$ with RCPs.

Variation: The annual variance $33 \%$ in the past was decreased to $29.8 \%$ in the present and will decrease to 29 $31 \%$ in future depending upon the model. Seasonally during Kharif, the variance of $44.1 \%$ in the past was deceased to $37.8 \%$ in present, and $16.3 \%$ with RCM, $34.0 \%$ with ClimGen and $2.7-3.5 .0 \%$ with RCPs in future. During Rabi variance of $50.1 \%$ in the past would decrease to $37 \%$ during present, and $28.9 \%$ with RCM, $36.0 \%$ with ClimGen and $20.3 \%$ in RCPs in future.

Time series trends: Time trend of rainfall at annual scale was increasing in the past, decreasing in the present and increasing in future time series with RCM and ClimGen models (Table 3b). Seasonally, in both Kharif and Rabi seasons, the time trends were increasing in the past as well as future time series, however, it is decreasing in the present. On the whole the time trend at monthly scale for rainfall are trendless and non-significant except significant increasing in March, April, June and July with RCM model, and in June and July with ClimGen.

\section{Frequency of days above ceiling and below base critical temperatures}

Over times with change in Tmax and Tmin in different time series i.e. from past to future, the number of days (averaged across years) above ceiling and below critically low temperatures those restrain yield in rice and wheat crops were altered. For instance in rice crop, days having Tmax $>37^{\circ} \mathrm{C}$ during crop growth have decreased by 7.5 days in the present and 4.6 days in future time series with ClimGen model (Table 4). With RCP numbers of days have increased by $1.8-4.3$ days. The number of days $>34^{\circ} \mathrm{C}$ during flowering to anthesis have decreased by 2.8 days in present and 3.0 6.5 days in future time series. The number of days having Tmin $>25^{\circ} \mathrm{C}$ have increased from 52.9 during past to 75.6 during present and 77.7-109.4 days during future time series. There was no change in number of days below lower critical temperature $\left(<15^{\circ} \mathrm{C}\right)$ that can affect the rice yield. During the wheat crop with change in Tmax, mean of days with temperature $>29^{\circ} \mathrm{C}$ were 27.3 was increased to 30.5 days in present and 31.9-55.8 days in future time series. Likewise during grain development and formation (120-150 days after sowing) 0.2 days with temperatures $>34^{\circ} \mathrm{C}$ were in past time series was increased to 1.1 days in present and $0.0-1.9$ days in future time series. With $\operatorname{Tmin}>11^{\circ} \mathrm{C}, 48.8$ days were increased to 65.8 in present and 66.9 to 81.6 days in future. Correspondingly the days $<3^{\circ} \mathrm{C}$ were 12.5 in the past time series which decreased to 6.2 in present and 0 18.9 in the future time series, respectively.

As changes in the climate are likely to influence spatial and seasonal trends of air temperature and rainfall, it will subsequently affect crop phenology, physiology and yield in different crops (Jalota and Vashish at, 2016; Jalota et al., 2018; Parry, 1990). Each of these crop processes works properly at apposite temperature range. For Instance vegetative growth at $30-36^{\circ} \mathrm{C}$ and germination of pollens at $33-34^{\circ} \mathrm{C}$ (Chahal et al., 2007), fertility of filled grains at anthesis at $31^{\circ} \mathrm{C}$ (Matsui et al., 1997) etc. Departure from these apposite temperatures and their longer exposure retard the phenological, physiological and reproduction processes and ultimately yields. For example, high temperature during grain filling of rice though enhance the grain dry matter increase rate, but yield is reduced because enhancement in dry matter increase is insufficient to completely compensate for the concomitant reduced grain filling period (Kobata and Uemuki, 2004). In the rice crop, increased seasonal or/ and at particular stage temperature is likely to decline yield by increasing crop respiration relatively more than photosynthesis, decreased nutrient absorption (Matasubayashi, 1965), less germination of pollens and reduced pollination and grain number (Mackill et al., 1982), high spikelet sterility (Haris et al., 2011) or less sink capacity (Kobata and Uemuki, 2004). Significant decline in rice yield with rise in night time temperature because of higher rates of respiration has also been documented in the literature (Peng et al., 2004). In addition to temperature yield also may be affected by probability of occurrence of rain as it damages/ washes away the pollens during flowering to anthesis period and thus affect the pollination and fertilization, and resulting in sterile spikelets (Chahal et al., 2007). In case of wheat the yield is not affected if seasonal temperature variation remains within the range of optimum temperature i.e. Tmax from $21.5-24.4^{\circ} \mathrm{C}$ and $\mathrm{Tmin}$ from $8.5-10.2^{\circ} \mathrm{C}$ as suggested by Porter and Gawith (1999) and is affected by the elevated temperature (Pittock, 2003) as well as frequency of the days with $\operatorname{Tmax}>27^{\circ} \mathrm{C}, \mathrm{Tmin}>11^{\circ} \mathrm{C}$ during crop period, and more number of days of higher terminal temperature $\left(\mathrm{e}^{\prime \prime} 34^{\circ} \mathrm{C}\right)$ during 120-150 days (Vashisht et al., 2019). More number 
of days with higher terminal temperature $\left(\left(>34^{\circ} \mathrm{C}\right)\right.$ shortens grain-filling duration and slows photosynthesis and grainfilling rates (Ritchie and NeSmith, 1991). The increased temperature decreases crop production mainly due to reduction in the length of the growing period of wheat (Liu et al., 2010). More number of days with d" $3^{\circ} \mathrm{C}$ hinders the growth of wheat crop by retarding physiological processes including photosynthesis, respiration, nutrient movements, transpiration that negatively affects plants growth (Gill and Tuteja, 2010). Increased rainfall improves physiological processes like ET, photosynthesis and nutrient uptake etc. and ultimately yield in wheat (Chen et al., 2010).

\section{CONCLUSIONS}

In a location of central Punjab (India), where rice (Oryza sativa L.)-wheat (Triticum aestivum L.) is a dominant cropping system, the magnitude of elevated temperature as well as frequency of days with yield restraining temperature are increasingwith global warming. The knowledge of magnitude and frequency of days above ceiling and below critically low temperatures during growth period as well as reproductive stages of crops will facilitate heat stress management by developing tactile and strategic adaptation measures such as shifting planting dates and introduction of new crops and varieties for future apart from introducing antioxidant defense system, increasing heat shocking proteins and developing stay-green genotypes (which maintain leaf chlorophyll and photosynthetic capacity at high temperature) through genomics.

\section{REFERENCES}

Bal, S.K., Choudhury, B.U., Sood, A., Jalota, S.K. and Singh, H. (2008). Evaluation of ClimGen model to generate weather parameters in different climatic situations in Punjab. J. Agrometeorol., 10(1): 73-79.

Chahal, G.B.S., Sood, A., Jalota S.K., Chaudhary, B.U. and Sharma,P.K. (2007). Yield, evapotranspiration and water productivity of rice (Oryza sativa L.) - wheat (Triticumaestivum L.) in Punjab (India) as influenced by transplanting date and weather. Agric. Water Manage., 88:14-22.

Chen, C., Wang, E. and Yu, Q. (2010). Modelling the effects of climate variabilityand water management on crop water productivity and water balance in the North China Plain. Agric. Water Manage., 97:1175-1184.

Gill, S.S., and Tuteja, N. (2010). Reactive oxygen species and antioxidant machinery in abiotic stress tolerance in crop plants. Plant Physiol. Biochem., 48: 909-930.

Haris, A., Chhabra, P. and Biswas, S. (2011). Modeling the Impact of anticipated change on wheat yields in different agro-climatic zones of eastern India. J. Agrometeorol., 13:116-118.

Hillel, D. and Rosenzweig, C. (2013). Handbook of climate change and agro ecosystems. Imperial College Press. https://doi.org/10.1002/joc.1602, 200.

Jalota, S.K., Kaur, H., Kaur, S. and Vashisht, B.B. (2013). Impact of climate change scenario on yield, water and nitrogen -balance and -use efficiency of rice-wheat cropping system. Agric. Water Manage., 116: 29-38.

Jalota, S.K., Kaur, H., Ray, S.S., Tripathy, R., Vashisht, B.B. and Bal, S.K. (2013). Past and General Circulation Modeldriven future trends of climate change in Central Indian Punjab: ensuing yield of rice-wheat cropping system. Current Sci., 104(1): 105-110

Jalota, S.K. and Vashisht, B.B. (2016). Adapting cropping systems to future climate change scenario in three agroclimatic zones of Punjab, India. J. Agrometeorol., 18: $48-56$.

Jalota, S.K., Vashisht, B.B., Sharma, S. and Kaur S. (2018). Understanding climate change impact on crop productivity and water balance. Academic Press, ELSEVIER(ISBN: 978-0-12-809520-1).

Kang, M.S. and Banga, S.S. (2013). Combating climate change: An agricultural perspective.CRC Press.

Kendall, M.G. (1975). Rank Correlation Methods. London: Charles Griffin, pp. 160.

Kobata, T. and Uemuki, N. (2004). High temperatures during the grain filling period do not reduce the potential grain dry matter increase of rice. Agron. J., 96:406-414.

Leander, R. and Buishand, T.A. (2007). Resampling of regional climate model output for the simulation of extreme river slopes. J. Hydrol., 332:487-496.

Liu, Y., Wang, E., Yang, X. and Wang, J. (2010). Contributions of climatic and crop varietal changes to crop production in the North China Plain, since 1980. Global Change Biol., 16: 2287-2299.

Mackill, D.J., Coffman, W.R. and Rutger, L.J. (1982). Pollen shedding and combining ability for high temperature tolerance in rice. Crop Sci., 20:730-733. 
Mann, H.B. (1945). Nonparametric tests against trend. Econometrica, 13:245-259.

Matasubayashi, M. (1965). Theory and practices of growing rice. Fuji Publishing Company, Tokyo.

Matsui, T., Omasa, T. and Horie, T. (1997). High temperature induced spikelet sterility of japonica rice at flowering in relation to air temperature, humidity and wind velocity. Jap. J. Crop Sci., 66:449-455.

Parry, M.N. (1990). Climate change and world agriculture.Earthscan, London.

Peng, S.B., Huang, J.L., Sheehy, J.E., Laza, R.C., Visperas, R.M., Zhong, X., Centeno, G.S., Khush, G.S. and Cassman, K.G. (2004). Rice yields decline with higher night temperature from global warming. PNAS 101:99719975.

Pittock, B. (2003). Climate Change: AnAustralian Guide to the Science and potential of Impacts. Department for the
Environment and Heritage. Australian Green House Office, Canberra,ACT. http://www.greenhouse.gov.an/ science/guide.index.html.

Porter, J.R. and Gawith, M. (1999). Temperature and the growth and development of wheat: a review. Eur. J. Agron., 16:23-36.

Ritchie, J.T. and NeSmith, D.S. (1991). In: Modeling Plant and Soil Systems Vol. 31 (eds. Hanks J and Ritchie J.T) 529 (ýASA, 1991).

Sen,P.K. (1968). Estimates of the regression coefficient based on Kendall's tau. JASA., 63: 1379-1389.

Stockle, C.O., Campbell, G.S. and Nelson, R. (1999). Clim Gen Manual, Biological Systems. Engineering Department, Washington State University, Pullman, WA28 pp.

Vashisht, B.B., Maharjan, B. and Jalota, S.K. (2019). Management practice to optimize wheat yield and water use in changing climate. Arch. Agron. Soil Sci. Doi.dg/ 10.1080/3650340.2019.1578957. 